Special issue of the 2nd International Conference on Computational and Experimental Science and Engineering (ICCESEN 2015)

\title{
An ESR Study on 2,4 Diaminotoluene Exposed to Gamma Rays and Application of Machine Learning
}

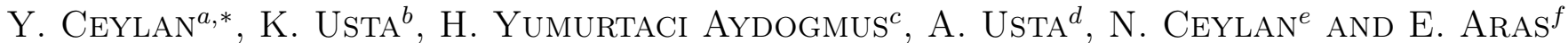 \\ ${ }^{a}$ Selcuk University, Department of Physics, Konya, Turkey \\ ${ }^{b}$ Alanya Alaaddin Keykubat University, Department of Metallurgical and Materials Engineering, Antalya, Turkey \\ ${ }^{c}$ Alanya Alaaddin Keykubat University, Department of Industrial Engineering, Antalya, Turkey \\ ${ }^{d}$ Alanya Alaaddin Keykubat University, Department of Mechanical Engineering, Antalya, Turkey \\ ${ }^{e}$ Giresun University, Department of Chemistry, Giresun, Turkey \\ ${ }^{f}$ Gazi University, Department of Physics, Ankara, Turkey
}

\begin{abstract}
The polycrystals of 2,4 diaminotoluene were produced by slow evaporation of solvent. The polycrystalline samples were exposed to ${ }^{60} \mathrm{Co}$ gamma rays with dose rate of $0.950 \mathrm{kGy} / \mathrm{h}$, at room temperature, for $12,24,48$, and 72 hours. The electron paramagnetic resonance measurements were carried out on these samples in the temperature range between $298 \mathrm{~K}$ and $400 \mathrm{~K}$. No electron paramagnetic resonance signal was observed in the samples irradiated for 12, 24, 48 hours. Two types of radicals were detected using ESR spectrometer in the sample irradiated for $72 \mathrm{~h}$. These radiation damage centers were called RI and RII. The average values of $g$ and the hyperfine coupling constant were calculated. This study also investigates the potential usage of machine learning methods and aims to test the success of these methods and to select the best method.
\end{abstract}

DOI: 10.12693/APhysPolA.130.184

PACS/topics: 87.66.Uv, 36.20.Kd, 39.30.+w, 33.35. $+\mathrm{r}$

\section{Introduction}

Aromatic amine groups are used as industrial chemicals and they are environmental pollutants. 2,4 diaminotoluene appertain to amine group. This chemical material is a synthetic intermediate [1] and it is used in the plastics industries and in the production of dyes nowadays [2]. 2,4-diaminotoluene has exhibited toxic properties in liver tissues [3]. Due to toxic properties of the aromatic amine groups, investigations of biological activities of the amine groups have been extensive. International Agency of Research on Cancer (IARC) has concluded that this compound is likely to be a human carcinogen. However, no information about the mechanism underlying the toxicity of amine groups is available.

In our study, we have focused on the fact that irradiation has a significant impact on the materials [4]. Ionizing radiation is able to kill the pathogens in contaminated foods. However, irradiation can results in breaking of bonds and changing of structural properties of the samples [5-7]. We have used electron paramagnetic resonance (EPR) method to study the radical formation mechanisms in 2,4 diaminotoluene exposed to radiation. The EPR technique has been frequently used for identification of radiation damage centers in organic and inorganic substances [8-10]. In this study we also present the comparison of different machine learning methods to test the performance and to select the best method, which could be implemented theoretically. In our previous paper [11] we used a large data set. In the present case

\footnotetext{
* corresponding author; e-mail: yceylan@selcuk.edu.tr
}

the number of data was limited to three data sets and we wanted to test the performance of machine learning methods in this case. Unlike in our previous work, the results of training and tests were compared separately for two data sets and in this way the best method has been selected.

\section{Material and methods}

\subsection{Experimental}

2,4 diaminotoluene was purchased from Sigma-Aldrich. Polycrystal formulations for each test chemical were produced in laboratory. The samples were irradiated for 12 , 24, 48 and $72 \mathrm{~h}$ using ${ }^{60} \mathrm{Co} \gamma$-ray source with dose rate of $0.950 \mathrm{kGy} / \mathrm{h}$. The measurements of EPR were made using Bruker EMX 081 EPR spectrometer. The temperature measurements were carried out between $298 \mathrm{~K}$ and $400 \mathrm{~K}$ using a Bruker temperature control unit. During EPR measurements the modulation frequency was $100 \mathrm{kHz}$ and the modulation amplitude was $2 \mathrm{G}$.

\subsection{Theoretical}

\subsubsection{Machine learning method}

Machine learning is the common name of the computer algorithms that model a given problem according to the data from the environment of the problem. Machine learning is a method of data analysis which includes automatic computing procedures based on logical or binary operations [12]. Artificial neural networks, decision trees, bayesian networks, support vector machines are examples of machine learning methods. In the application of machine learning methods, available data are divided into two sets. The first set of data is used for the "training" 
(learning) phase, and then the success of the learning is "tested" using second data set.

\section{Results and discussion}

EPR signals were measured on the sample irradiated for 72 hours. Following the irradiation of 2,4 diaminotoluene, the EPR measurements were performed between $298 \mathrm{~K}$ and $400 \mathrm{~K}$. It was observed that the spectra depend slightly on the temperature. As the signal observed at $298 \mathrm{~K}$ consisted of four lines, the signal observed at $340 \mathrm{~K}$ consisted of six lines. Temperature affects localized or unlocalized state of an unpaired electron. Once the general condition of the spectrum was observed, it was seen that there was no essential change in the spectrum.

The temperature dependence of the EPR lines is shown in Fig. 1.
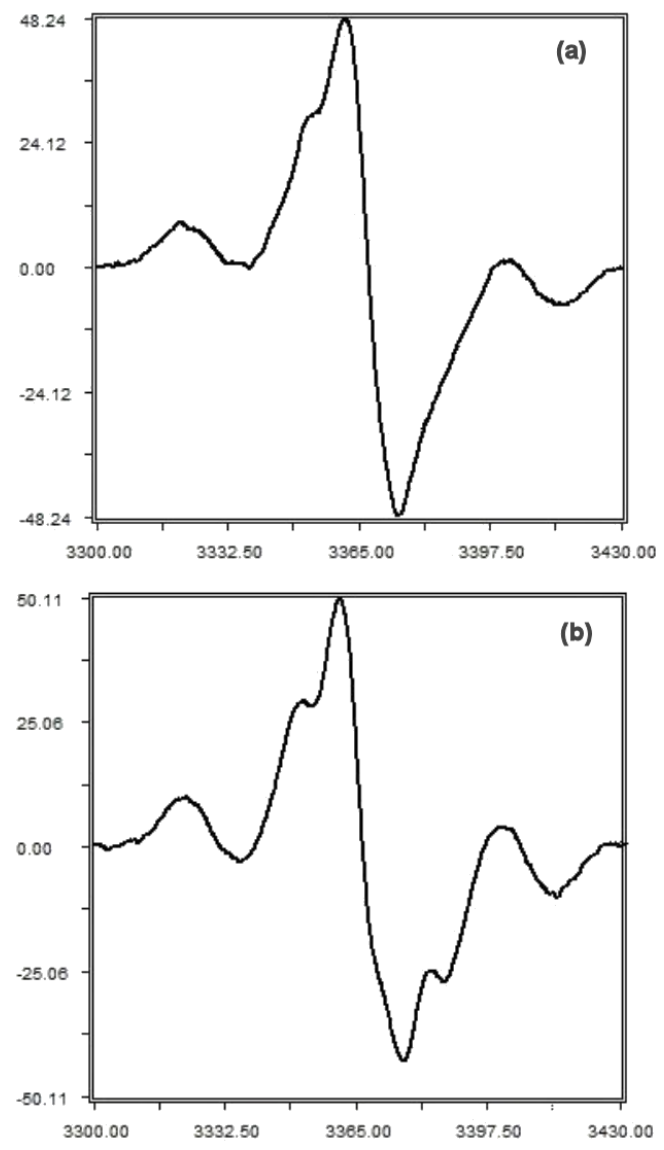

Fig. 1. The EPR spectrum of $\gamma$-irradiated 2,4 diaminotoluene at (a) $298 \mathrm{~K}$ and (b) $340 \mathrm{~K}$.

When the recorded spectra were analysed, it was found that EPR lines belong to two radicals. According to the molecular structure of the sample and the recorded spectra, for the first radical, the contributions to the spectra came from $\mathrm{H}_{\mathrm{a}}$ and $\mathrm{H}_{\mathrm{b}}$ protons, magnetically equivalent; and then from the $\mathrm{N}_{\mathrm{c}}$ proton. Similarly, for the second radical, contributions to the spectra came from $\mathrm{H}_{\mathrm{x}}$ atom and from $\mathrm{N}_{\mathrm{y}}$ proton (Fig. 2). These results were verified by computer simulation results shown in Fig. 3. The principle values and the $g$-tensors are given in Table I.<smiles>Cc1ccc(N)cc1N</smiles>

Fig. 2. Molecular structure of radical I (a) and radical II (b).

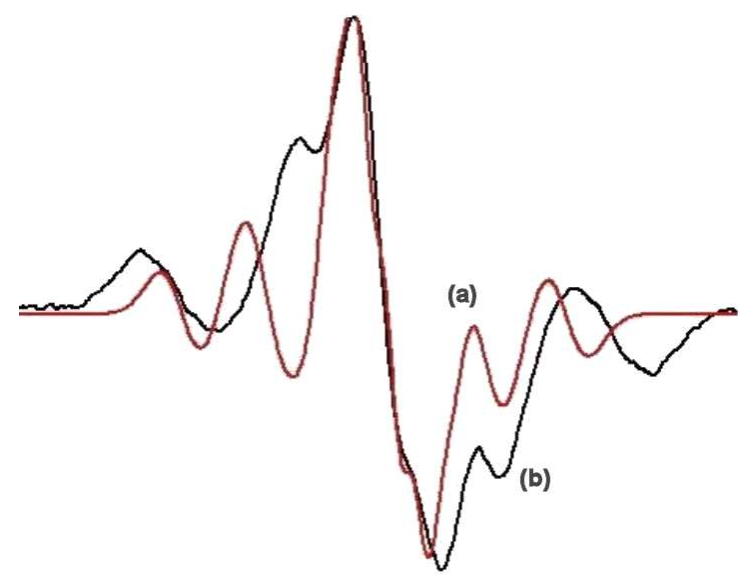

Fig. 3. The EPR spectrum (a) and its simulation (b).

TABLE I

The EPR parameters of irradiated 2,4 diaminotoluene.

\begin{tabular}{c|c|c}
\hline \hline & Radical I & Radical II \\
\hline \multirow{2}{*}{ Hyperfine constant } & $N=20 \mathrm{G}$ & $N=2.87 \mathrm{G}$ \\
& $2 H=14.65 \mathrm{G}$ & $H=7.15 \mathrm{G}$ \\
$g$-value & 2.0077 & 2.0011
\end{tabular}

At this theoretical implementation phase, in total three data sets were used in this study and two of them $(320 \mathrm{~K}$ and $400 \mathrm{~K}$ ) were chosen to determine the methods. In the application of machine learning methods, firstly two data sets, not including their values, were used for training for ten-fold cross validation in the Weka Explorer, to determine the methods having the smallest error values. Seven methods having error rate less than $30 \%$ were listed and statistical results are shown for each training set in Table II.

Success of the top five (error rate less than 15\%) learning methods was tested separately for $320 \mathrm{~K}$ and $400 \mathrm{~K}$. Statistical values of the test phase are listed in Table III for each test set. 
TABLE II

Statistical values of the training phase.

\begin{tabular}{c|c|c|c|c|c|c}
\hline \hline Method & $\begin{array}{c}\mathrm{T} \\
{[\mathrm{K}]}\end{array}$ & $\begin{array}{c}\text { Correlation } \\
\text { coefficient }\end{array}$ & $\begin{array}{c}\text { Mean absolute } \\
\text { error }\end{array}$ & $\begin{array}{c}\text { Root mean } \\
\text { squared error }\end{array}$ & $\begin{array}{c}\text { Relative } \\
\text { absolute error [\%] }\end{array}$ & $\begin{array}{c}\text { Root relative } \\
\text { squared error[\%] }\end{array}$ \\
\hline \multirow{2}{*}{ Lazy IBk } & 320 & 0.9998 & 4.346 & 7.259 & 1.729 & 1.920 \\
& 400 & 0.9998 & 4.477 & 7.407 & 1.720 & 1.920 \\
\hline Bagging & 320 & 0.9993 & 9.281 & 13.684 & 3.692 & 3.620 \\
REPTree & 400 & 0.9990 & 10.745 & 17.473 & 4.120 & 4.530 \\
\hline \multirow{2}{*}{ REPTree } & 320 & 0.9988 & 12.280 & 18.712 & 4.885 & 4.950 \\
& 400 & 0.9984 & 14.309 & 21.830 & 5.482 & 5.660 \\
\hline \multirow{2}{*}{ M5P } & 320 & 0.9952 & 25.275 & 40.607 & 10.054 & 10.742 \\
& 400 & 0.9955 & 26.804 & 41.029 & 10.269 & 10.638 \\
\hline \multirow{2}{*}{ M5Rules } & 320 & 0.9942 & 28.589 & 41.453 & 11.372 & 10.966 \\
\hline Regression & 400 & 0.9915 & 35.753 & 53.161 & 13.698 & 13.783 \\
\hline by discretization & 400 & 0.9884 & 49.898 & 57.455 & 19.849 & 15.199 \\
MLP & 320 & 0.9885 & 50.070 & 58.289 & 19.180 & 15.110 \\
\hline regressor & 400 & 0.9750 & 69.895 & 85.635 & 22.157 & 17.887 \\
\end{tabular}

TABLE III

Statistical values of the test phase.

\begin{tabular}{c|c|c|c|c|c|c}
\hline \hline Method & $\begin{array}{c}\text { T } \\
{[\mathrm{K}]}\end{array}$ & $\begin{array}{c}\text { Correlation } \\
\text { coefficient }\end{array}$ & $\begin{array}{c}\text { Mean absolute } \\
\text { error }\end{array}$ & $\begin{array}{c}\text { Root mean } \\
\text { squared error }\end{array}$ & $\begin{array}{c}\text { Relative } \\
\text { absolute error [\%] }\end{array}$ & $\begin{array}{c}\text { Root relative } \\
\text { squared error [\%] }\end{array}$ \\
\hline Lazy & 320 & 0.9848 & 46.708 & 67.409 & 17.662 & 17.598 \\
IBk & 400 & 0.9914 & 33.712 & 51.670 & 13.749 & 14.062 \\
\hline Bagging & 320 & 0.9857 & 44.964 & 64.874 & 17.003 & 16.936 \\
REPTree & 400 & 0.9925 & 31.615 & 48.823 & 12.894 & 13.287 \\
\hline \multirow{2}{*}{ REPTree } & 320 & 0.9850 & 46.426 & 66.677 & 17.556 & 17.407 \\
& 400 & 0.9914 & 33.401 & 51.557 & 13.622 & 14.031 \\
\hline \multirow{2}{*}{ M5P } & 320 & 0.9846 & 48.721 & 67.711 & 18.424 & 17.677 \\
& 400 & 0.9437 & 74.516 & 123.991 & 30.390 & 33.743 \\
\hline \multirow{2}{*}{ M5Rules } & 320 & 0.9846 & 50.791 & 70.618 & 19.206 & 18.436 \\
& 400 & 0.8968 & 98.510 & 170.260 & 40.176 & 46.335
\end{tabular}

While Lazy IBK method was having the best results in the training phase, Bagging REPTree method had better results than Lazy IBK by a narrow margin. Comparison of actual values and predicted values obtained by Lazy IBK and by Bagging REPTree are shown in Figs. 4 and 5 respectively, for test phase.

\section{Conclusions}

We have investigated the EPR spectral parameters of irradiated 2,4 diaminotoluene. This investigation has pointed out that the unirradiated substance and substance irradiated for 12, 24 and 48 hours do not give any EPR signal, however two types of radicals were produced in the sample irradiated for $72 \mathrm{~h}$. It was observed that the spectra depend slightly on temperature. Theoretical results obtained using machine learning methods have shown that the machine learning methods can be used

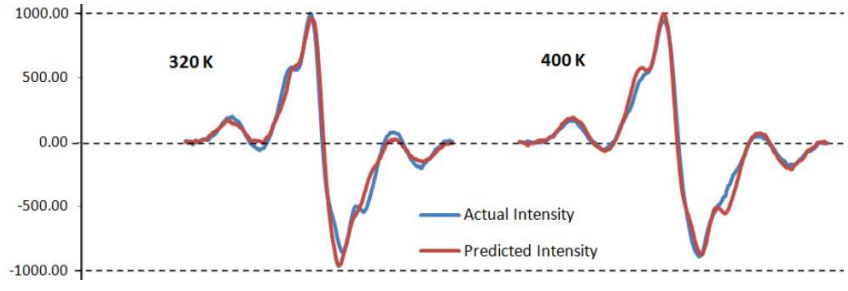

Fig. 4. Comparison of actual and predicted values for test phase (Lazy IBK method).

successfully for subsequent studies with large and small data sets. While Lazy IBK method was having the best results in training phase, Bagging REPTree method had better results than Lazy IBK in the test phase. The difference between the results obtained in the test phase of Lazy IBK and Bagging RepTree are very low, so we can state that both of them can be used successfully. 


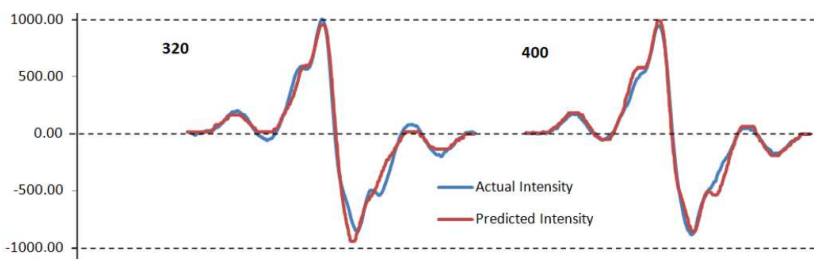

Fig. 5. Comparison of actual and predicted values for test phase (Bagging REPTree method).

\section{Acknowledgments}

This study was partially supported by Alanya Alaaddin Keykubat University, and the Scientific Research Projects Coordination Centers of Selcuk, Gazi Universities, Turkey.

\section{References}

[1] US Department of Health, Education, and Welfare Bioassay of 2,4-diaminotoluene for possible carcinogenicity, NC1 Carcinogenesis Technical Report Series, No. 162, NTIS, Springlield, VA 1979.

[2] IARC, Monographs on the evaluation of the carcinogenic risk of chemicals to humans. Some aromatic amines and related nitro compounds. Hair dyes, coloring agents and miscellaneous industrial chemicals, Vol. 16, World Health Organization, Lyon, France 1978, p. 400.
[3] B.N. Ames, H.O. Kammen, E. Yamasaki, Proc. Natl. Acad. Sci. U.S.A. 72, 2423 (1975).

[4] N.D. Yordanov, K. Aleksieva, Radiat. Phys. Chem. 78, 213 (2009).

[5] D.J.T. Hill, K.J. Thurecht, A.K. Whittaker, Radiat. Phys. Chem. 67, 729 (2003).

[6] S. Indira, B. Sanjeeva, V. Sridhar, G. Punnaiah, Radiat. Eff. Defects Solids 160, 145 (2005).

[7] N. Subbarami, B. Sanjeeva, A. Jadhav, G. Punnaiah, V. Sridhar, S. Veera, Radiat. Eff. Defects Solids 157, 411 (2002).

[8] W. Gordy, Theory and Applications of Electron Spin Resonance, John Wiley \& Sons, New York 1980

[9] S.Ya. Pshezhetskii, A.G. Kotov, EPR of Free Radicals in Radiation Chemistry, John Wiley \& Sons, New York 1973.

[10] E. Aras, A. Usta, S. Erturk, B. Asik, Radiat. Eff. Defects Solids 167, 157 (2012).

[11] Y. Ceylan, K. Usta, A. Usta, H. Yumurtaci Aydogmus, A. Guner, J. Mol. Struct. 1100, 180 (2015).

[12] D. Michie, D.J. Spiegelhalter, C.C. Taylor, Machine Learning, Neural and Statistical Classification, Ellis Horwood Limited, 1994. 